\title{
Pre-Adoption Diagnosis of the Intelligence Process in Organizations: A Delphi Study with Intelligence Practitioners
}

Amanda Cainelli ${ }^{1}$ Raquel Janissek-Muniz ${ }^{1}$

${ }^{1}$ Universidade Federal do Rio Grande do Sul, Porto Alegre, RS, Brazil

Received 10 October 2018. This paper was with the authors for three revisions. Accepted 2 November 2019. First published online 5 December 2019.

Clarissa Carneiro Mussi and an anoynimous contributor served as the associate editors for this article.

Editorial assistant: Luciane Kato Kiwara

Editor-in-chief: Carlo Gabriel Porto Bellini 


\begin{abstract}
In turbulent and competitive scenarios, strategic intelligence is a crucial process for organizations to reduce uncertainties during decision-making and to anticipate changes that may affect their performance and sustainability. Despite the relevance of the activity, continuous and structured processes based on intelligence in organizations are not a reality due to the difficulty of implementing and formalizing it. Executing a diagnosis to evaluate conditions that precede the adoption of a structured intelligence activity allows companies to recognize their efficiency to perform monitoring, to further improve or implement it. This paper explores organizational, informational, individual, technological and material conditions that precede the adoption of the intelligence process, reviews six diagnostic models and proposes a diagnostic tool to evaluate issues that must be considered in advance. The Delphi method was used to exploit opinions among 30 intelligence practitioners in order to define which conditions of the process should be evaluated before its adoption in companies. As a result, this work contributes to filling the gap observed in the literature about the motivation to initiate the intelligence process in organizations and presents a formalized tool to evaluate its pre-adoption stage.
\end{abstract}

Keywords: pre-adoption; structured intelligence process; diagnostic tool; delphi. 


\section{Introduction}

Over the past 30 years, intelligence applied to business has become a fundamental component of the informational infrastructure of companies and a prerequisite for organizational success (Davenport, Harris, \& Morison, 2010; Gilad \& Fuld, 2016). Also known as environmental scanning (Aguilar, 1967), strategic foresight (Tsoukas \& Shepherd, 2004) or strategic scanning (N. Lesca, Caron-Fasan, Aguirre, \& Chalus-Sauvannet, 2015), intelligence is an essential process to identify signals in the environment (changes and events) that must be observed, captured and interpreted so that action can be taken in advance (Andriotti, Freitas, \& Janissek-Muniz, 2008; Hakansson \& Nelke, 2015). These signals must be detected early in the external environment, in time to mitigate their impacts (Russo, Sbragia, \& Abraham, 2017). When done systematically, the intelligence process allows production of value-added information and support for strategic decisions, which is particularly relevant for organizations that wish to maintain a lifelong sustainable competitive advantage (Choo, 1999; Tarapanoff, 2006).

The intelligence process should be structured to transform scattered and dissociated information into actionable intelligence (Hakansson \& Nelke, 2015). Systematization of the intelligence process provides increased quality of the information in order to identify targets based on the organizational priorities and strategy, reduce information duplicity, raise the probability of identifying opportunities and threats, and increase decision making in strategic planning (Gilad \& Gilad, 1985; McGonagle \& Vella, 2002; Sassi, Frini, Abdessalem, \& Kraiem, 2015).

Although the importance of the structured process is recognized, there are still discontinuous, informal and non-institutionalized intelligence practices in organizations (Borges \& JanissekMuniz, 2017; Davis, 2008; Gilad \& Fuld, 2016; Mayer, Steinecke, Quick, \& Weitzel, 2013). Often, process structuring is considered a complex task by companies, and this difficulty may be linked to various aspects of the external environment that need to be constantly monitored, requiring a significant effort by managers and decision-makers (Janissek-Muniz, 2016; Vidigal, 2013).

The intelligence process adoption requires a raise in executives' sensibility and awareness of monitoring practices so that their companies can draw plans to achieve the desired formalization of the process (Brouard, 2007; H. Lesca, 2003). Although generally neglected (Gilad, 2016), this evaluation can indicate improvements and actions for intelligence activity success and continuity (Caron-Fasan \& Janissek-Muniz, 2002).

There are few studies about the stage prior to the intelligence process adoption (N. Lesca et al., 2015) that support the fact that it is in this important stage that organizations are sensitized and awareness is created, as well as knowledge and interest about the need to observe the environment. This is the reason why it is important to recognize, a priori, activities and conditions that can influence the success of the process (Janissek-Muniz, 2016; Luzipo, Van Biljon, \& Herselman, 2015). This understanding can potentially avoid future problems, reduce costs and time, reduce failure risks, and prepare an environment suitable to receive the intelligence process (Verville, Barnadas, \& Halingten, 2005). Therefore, the motivation to adopt the intelligence

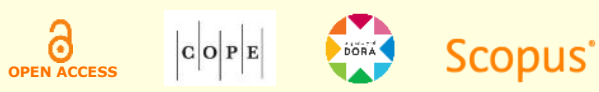


process is one of the subjects that still need to be explored in the literature: the knowledge regarding the internal and external conditions that precede this adoption or what leads organizations to initiate this process have yet to be investigated (Iden, Methlie, \& Christensen, 2017). Gilad (2016) points out that is important to understand information needs and business practices before adopting an effective intelligence process, because the motivation that drives the process implementation is a valid indicator of future, costs and effectiveness.

If organizations can identify beforehand the main issues related to organizational, informational, human and technological conditions that must be improved in order to adopt a structured intelligence process, they can lead to the success and continuity of the intelligence activity $(\mathrm{N}$. Lesca et al., 2015). Through mapping and recognizing the points that need improvement, organizations can better prepare themselves to receive and structure the process, since the absence of this prior knowledge is one of the main reasons for the discontinuity and weakening of the activity (Herring, 1999). In this sense, the questions that guide this work are: how can anticipative evaluation be done, and which are the main conditions that must be evaluated in the preadoption stage of the intelligence process? In this way, this paper aims to present a diagnostic tool to evaluate conditions related to the structured intelligence process before it is adopted in companies. For all these reasons, this article explores the pre-adoption phase of the intelligence process considering the existing literature on Information Systems and Strategic Intelligence, aiming to identify prior conditions and build a framework of this stage. In order to identify such conditions, this study analyzes six diagnosis tools of the intelligence activity. As a result of the analysis, it will be possible to pose a set of questions through the Delphi method, in order to consolidate a diagnostic script to be applied in organizations before the intelligence process is installed. Finally, we present a tool to identify which improvements should be worked on to reach the structuring and success of the activity.

\section{Pre-adoption of the Intelligence Process}

The concept of intelligence refers to an organized process that helps organizations monitor and understand their business environment, compete successfully, and grow in a dynamic world in which executives need to be aware of external opportunities and threats in order to make decisions (Casagrande, Aguirre, \& Vuillon, 2015). In this context, information is the central resource of organizations (Rios \& Janissek-Muniz, 2014), and intelligence emerges as a formalized process that supports and works with strategy, contributing to business value and sustainable growth in companies (N. Lesca \& Caron-Fasan, 2008). Above all, the intelligence process is a systematic way of looking at the world outside the company by observing, collecting and interpreting information to provide decision-makers with elements that allow to anticipate imminent opportunities and dangers in order to deal effectively with them (Brouard, 2007). Studies have pointed out that this process is not only responsible for specifying which sectors should be monitored, but also for scanning valuable information related to threats and opportunities, indicating the tools to be used, incorporating analytical findings into executive decision-making and, in many cases, monitoring the environment (Mayer, 2012). Therefore, when incorporated into organizational processes, the intelligence process is necessary for

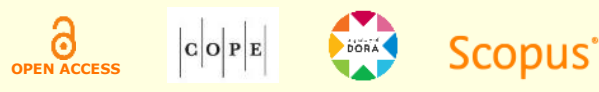


decision-maker success, as it produces relevant information that can be used to strategically position a company (Gilad \& Gilad, 1985; Kahaner, 1996).

Daft and Weick (1984) corroborate this idea and argue that any organization that has a structured intelligence process will be able to develop sensitivity in the analysis and interpretation of data and information, being able to not only act passively or in response to future trends in its environment, but rather influence it into a desired situation. According to Choo (2001), in order to carry out the intelligence process, it is necessary that the organization has an internal an ability to learn and interpret data and is aware of some questions about the search for information: the need for search; the manner or form that it will be sought; the destination or use of information; and the analysis on how this information impacts and is impacted by the context or situational dimension, organizational strategies and managerial aspects. The investigation on information can be inferred as capabilities, which can be considered Dynamic Capabilities, since they represent a set of skills that the organization develops internally in order to integrate, construct and reconfigure resources (structure and processes), as well as to adapt quickly to environmental changes (Teece, Pissano, \& Shuen, 1997).

As described earlier, because it is so inherent to the internal processes of each company, the stage that precedes the adoption of the intelligence process varies from one organization to another and depends on three underlying factors: objectives, corporate structure, and resources (Bartes, 2013; Gilad \& Gilad, 1985). External conditions (environmental turbulence and resource dependence); organizational issues (nature of the business and strategy pursued); informational conditions (availability and quality of information); personal issues (knowledge of the intelligence professional); and cognitive style can also influence intelligence process adoption (Choo, 2003). This is why before any intelligence operation begins, it is essential to know users' informational needs so that the actions can be well-conducted, considering that the absence of this knowledge is the main reason for poor intelligence processes, with low performance and demotivation of intelligence teams (Herring, 1999).

Another important element that can contribute to the success and sustainability of the intelligence process in organizations is prior contact with critical factors. Certain conditions, such as organizational, individual, informational, technological and material, can indicate barriers or drivers that may or may not be present in organizations and therefore should be analyzed in the pre-adoption stage of the structured intelligence process, as shown in Figure 1. 


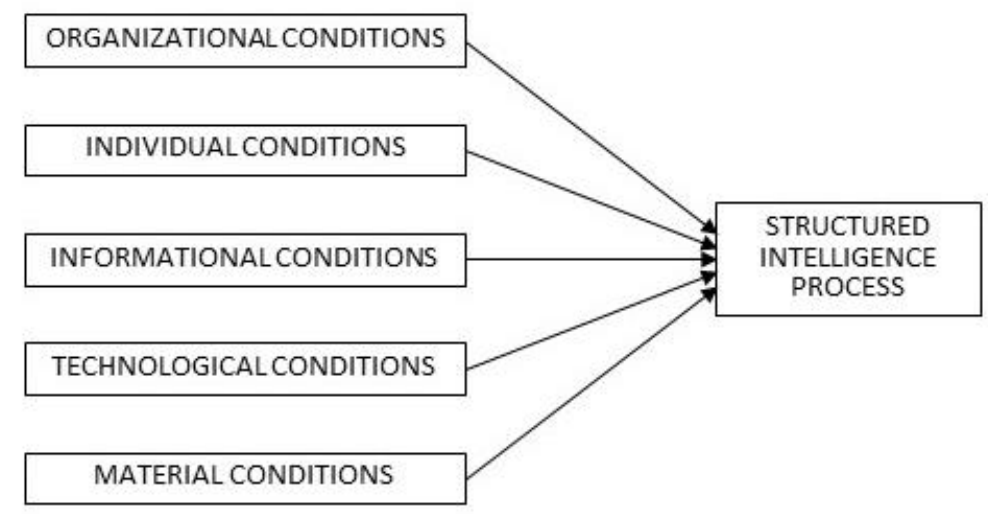

Figure 1. Pre-adoption conditions of the structured intelligence process

Given this, human, organizational, material and cultural resources emerge as central indicators of success or failure of an activity, such as choosing a leader, for example, who must be competent, legitimate and recognized by the people involved - team and top management - and the definition of the expected objectives of the project (Janissek-Muniz, 2016). The commitment to make intelligence a continuous activity requires, therefore, conditions that must be adapted to the specific goals and needs of the company so that the process can be an organic part of it (Bartes, 2013; Caron-Fasan \& Janissek-Muniz, 2001; Gilad \& Gilad, 1985). The conditions to achieve success in the pre-adoption stage of the structured intelligence process will be discussed in the following section.

\section{Organizational conditions}

According to Bartes (2013), the main reason of failure when organizations implement an intelligence process is not creating favorable conditions for the success of the activity, such as providing education and training, equipment, tools, and sources of information. The process should be part of organizational strategic planning to support the development of competitive advantage or market position (Choo, 2003; Gilad \& Gilad, 1985; N. Lesca et al., 2015). According to studies in this area, by stimulating the information-driven culture, intelligence serves to fuel the innovation process, help market differentiation, and increase organizational competitiveness (Jaharuddin, Dato'Mansor, \& Yaakob, 2016; Janissek-Muniz, 2016; Marchand \& Hykes, 2007; N. Lesca et al., 2015; Xu \& Kaye, 2009).

Another reason for organizations to adopt strategic scanning is to do what other organizations are doing (N. Lesca et al., 2015). The comparison between organizations can be useful in task planning, in the definition of objectives and also in the recognition of resources limitations (human and financial, in order to conduct the activity), and so the intelligence process complexity is understood beforehand (Bartes, 2013; Gilad \& Gilad, 1985; Janissek-Muniz, 2016; N. Lesca et al., 2015). 
Support from top management, training, and user's commitment are also predictors of process adoption (Almeida, Lesca, \& Canton, 2016; Luzipo et al., 2015). The lack of support from top management in legitimizing a leader or a committee responsible for conducting the implementation of the intelligence process and the absence of budget can negatively impact its continuity (Almeida \& Hirata, 2016; Janissek-Muniz, 2016; N. Lesca et al., 2015).

\section{Individual conditions}

The sharing of knowledge at all levels should be a feature of the structured intelligence process to encourage diversity of interpretation and vision of the future within the company (Marchand $\&$ Hykes, 2007). Besides that, there is a need for an adequate leader profile, as well as specific skills, legitimacy and competence of the leader to motivate the execution and conduction of strategic scanning activity (Bartes, 2013; Janissek-Muniz, 2016; Mayer, 2012; N. Lesca \& CaronFasan, 2008). Also, there is still a lack of internal knowledge about the benefits and advantages of the process, which often leads to the unrealistic perception that the intelligence area will solve all company problems (Bartes, 2013). As individual pre-adoption conditions, the representative elements are linked to manager and staff having personal awareness, willingness and commitment that it is worth having an intelligence process, a positive attitude toward it, and the knowledge that the method is relevant (Gilad \& Gilad, 1985; Jalaldeen, Karin, \& Mohamed, 2009; JanissekMuniz, 2016; N. Lesca et al., 2015).

Another individual issue mentioned by H. Lesca (2003) is when the manager recognizes the importance of the process and wishes to implement it, but is blocked by his or her peers or superiors who do not adhere to it and are not sensitized about it. Borges and Janissek-Muniz (2017) also point out that there are managers who make decisions individually due to their position of power, despite an established structured intelligence process in the organization.

\section{Informational conditions}

The emergence of the currently available information volume is one of the most relevant issues about the need to implement intelligence processes (Fachinelli, Giacomello, Rech, \& Bertolini, 2013). Strategic information must be properly recognized and distributed in order to facilitate decision-making and deliver results (Marchand \& Hykes, 2007). Information distribution formats should be developed according to the needs of the company and the receivers (Rios \& Janissek-Muniz, 2014), because when the structure and the planning of dissemination are inadequate, they can impoverish the circulation of intelligence products and reduce confidence in the process (N. Lesca et al., 2015).

The adoption of strategic scanning process should respond to the need of capturing, sharing and analyzing information related to the current state and the evolution of the socioeconomic environment (N. Lesca \& Caron-Fasan, 2008). The necessity of adopting the process can be related to understanding the environment, solving a specific problem, or timely information for decision making, which characterizes the reactive mode (N. Lesca \& Caron-Fasan, 2008; N. Lesca

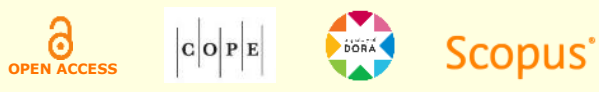


et al., 2015). Adoption may also be related to the need to explore the environment proactively, allowing the organization to address imminent dangers or possible opportunities, setting the anticipatory mode (Brouard, 2007; Gilad, 2016; H. Lesca, 2003; N. Lesca \& Caron-Fasan, 2008; Soliman \& Karia, 2017). Another mode is proposed by Janissek-Muniz (2004) when introducing the provocation of information as a complementary way of obtaining pertinent information through information generation, aiming at the establishment of collaborative channels.

\section{Technological and material conditions}

Although all forms of monitoring involve the search and use of information about the environment, supported or not by technological tools, the intelligence process can be complemented through digital platforms or based on a combination of tools for each of its stages (Baumard, 1997; Belmondo, 2008; Rios \& Janissek-Muniz, 2014). Technological solutions are relevant and can enhance the ability to appropriately manage information flows, with an infrastructure to support decision-making and the communication stage within the intelligence process (Calof \& Wright, 2008; Marchand, Kettinger, \& Rollins, 2001). On the other hand, intelligence platforms acquired by the organization are often expensive and underexplored by the teams (Bartes, 2013).

There is also the time factor related to the environmental monitoring process planning, considering that strategic information should arrive at the appropriate time for decision-making (H. Lesca, Cavalade, Darves, \& Deck, 1995). More recent studies, such as Janissek-Muniz (2016) and N. Lesca, Caron-Fasan, Aguirre and Chalus-Sauvannet (2015), indicate that the urgency to receive the intelligence products, the information overload during the process of collecting and the sorting for relevant information are other critical factors related to the time involved in the task.

\section{Intelligence Diagnostic Tools}

When results are obtained from diagnosis, they can provide the necessary motivation in the structuring and continuity of the intelligence process (H. Lesca et al., 1995), because diagnostic tools help raise awareness about monitoring practices and help expose their use, indicating where to focus efforts and resources to improve or shape the intelligence process (Brouard, 2007). In this sense, H. Lesca, Cavalade, Darves and Deck (1995) conducted one of the first studies to suggest a diagnostic tool for the intelligence process that helps smaller companies understand if they actually monitor their environment, what is the status of the activity and how they can improve it. The approach to monitoring has an anticipatory bias called prospective environmental scanning. The tool developed by the authors - FENNEC - aims to deliver a global diagnosis of the intelligence activity in a dashboard and can be applied in three situations: when there is already awareness of the need to monitor the environment; when top management executives wish to develop and monitor their progress on a regular basis; and, additionally, to provoke a rupture in the level of executive consciousness, sensitizing them to and raising interest in the potential of environmental scanning (H. Lesca et al., 1995).

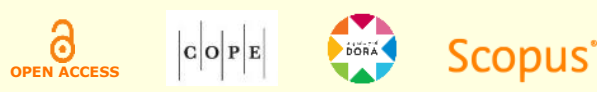


Marchand, Kettinger and Rollins (2001) propose an Information Orientation (IO) framework, a different diagnostic model developed to determine the level of effective information use by organizations and to identify areas where there could be improvements and consequently an increase in the level of intelligence process effectiveness. This can be noticed in companies that have reached maturity in the strategic use of information, aligning people, processes and technology practices with their business strategies, gaining competitive advantage and future leadership. This model allows these companies to be aware of their abilities to collect and share information in order to proactively participate in events not yet consolidated in the market (Marchand et al., 2001).

In another study, Brouard (2007) discusses the need to raise awareness of the intelligence process in organizations. The author argues that every company needs to know the status of its intelligence practices, so that it can be improved. Without evaluation, organizations cannot identify or focus on activities that require their attention to achieve established goals. In this sense, evaluating intelligence practices allows the organization to compare its real condition and the desired condition to direct activities and prioritize determinant actions. In his model, Brouard (2007) argues that the desired condition may be an ideal state based on the best practices or based on the association between strategic intelligence activities and specific organizational needs. The system proposed by the author evaluates four leading indicators of environmental scanning: types (technological, commercial, competitive, and social), context (structure, culture, management, and resources), organization (conduction, formalization, frequency, integration, diversification, intensity, and ethics), and process (cycle, planning, collection, analysis, dissemination, and evaluation).

In order for the intelligence process to become a continuous activity, Bartes (2013) reinforces the importance of creating appropriate human, organizational and material conditions for its development. He proposes a step-by-step diagnostic approach to its adoption in companies. As a premise, the author suggests considering who the recipients of the future area of intelligence will be, in order to define the level of importance and contribution that this area will have for the company. With these top management needs well-defined, the author details procedures for adopting the intelligence process. He suggests a methodological procedure inside and outside the organization: to set goals or indicators to evaluate the results of actions undertaken, to define projects or studies that will be delivered, to establish procedures for the implementation of the results of projects or studies, to define a feedback mechanism based on the results of the area, and to outline possible forms of cooperation with external organizations.

Gilad (2016) argues that understanding the difference between business needs and practices is imperative before an effective intelligence process is designed but points out that organizations often ignore this stage. From his corporate experience, the author recognizes that there are several critical elements to an effective intelligence process, and suggests anticipative procedures: to differentiate tactical information from strategic information needs for key executives; to map the existing flow of information into the organization by a network of informal experts; to determine key decision confluences where the intelligence professional must provide inputs to prevent losses or identify opportunities early enough to take advantage of them; to determine crucial meetings

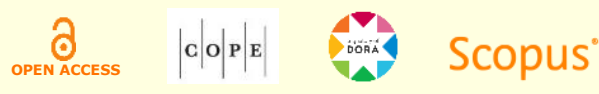


or planning committees to which the intelligence professional must have access; to establish an educational procedure so that all new or newly promoted executives can receive training on understanding and using strategic information; to assess patterns of intelligence use across multiple management layers; and to continuously reevaluate the process. Therefore, Gilad (2016) proposes a Motivation Test for Competitive Intelligence, since the motivation behind the intelligence process creation is a good indicator of its future, cost, and effectiveness. The questionnaire advises the organization to decide about initiating the intelligence process by evaluating whether it is worth spending time and effort or not.

In its global intelligence research, Strategic and Competitive Intelligence Professionals [SCIP] (2017) uses a questionnaire to understand intelligence practices around the world. The tool intends to offer an overview of who the professionals are, what they are doing and for whom they are doing intelligence. The instrument analyzes many aspects, such as structure and organization, focus, sources of information used, analytical techniques, communication methods, activity management, evaluation and innovation. As a diagnostic tool, results may indicate improvements in weak areas or opportunities to be explored. SCIP recommends that a look at the previous stage is fundamental to the continuity of the process, and a look at the latter stages reinforces the value and contributions of the area to the company.

As evaluative instruments, all six tools developed by the cited authors present, in their own way, questions related to the evaluation of organizational, individual, informational, technological and material conditions for adopting a structured intelligence process (Table 1).

Table 1

Diagnostic tools to evaluate the intelligence process

\begin{tabular}{lll}
\hline Article & Authors & Description \\
\hline $\begin{array}{l}\text { Fennec: a dashboard to evaluate environmental scanning within } \\
\text { businesses }\end{array}$ & $\begin{array}{l}\text { H. Lesca et al. } \\
(1995)\end{array}$ & $\begin{array}{l}\text { Questionnaire with open and } \\
\text { closed questions }\end{array}$ \\
\hline $\begin{array}{l}\text { Making the invisible visible: how companies win with the right } \\
\text { information, people, and IT }\end{array}$ & $\begin{array}{l}\text { Marchand et al. } \\
(2001)\end{array}$ & $\begin{array}{l}\text { Information Orientation } \\
\text { Framework (IO) }\end{array}$ \\
\hline $\begin{array}{l}\text { Development of an expert system on environmental scanning } \\
\text { practices in SME: tools as a research program }\end{array}$ & Brouard (2007) & $\begin{array}{l}\text { Prototype diagnostic system with } \\
\text { headlights }\end{array}$ \\
\hline The process of implementing competitive intelligence in a company & Bartes (2013) & List of procedures \\
\hline Motivation test for competitive intelligence & Gilad (2016) & Set of open questions \\
\hline SCIP questionnaire & SCIP (2017) & $\begin{array}{l}\text { Set of open and closed } \\
\text { questions }\end{array}$ \\
\hline
\end{tabular}

The diagnosis proposed by H. Lesca et al. (1995) and the SCIP questionnaire (2017) can be considered complete forms, since they comprise most of the pre-adoption conditions reported in the literature. However, the tools are not intended to explore the pre-adoption stage, but rather the activity itself, concerning questions to verify the degree of maturity, structuring, and the way

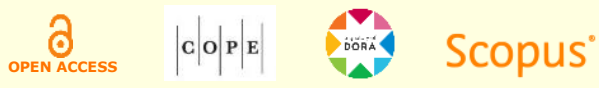


that organizations are conducting the intelligence process. The models by Marchand et al. (2001) and Brouard (2007) include some diagnostic questions, but they are combined with questions related to conducting the activity. The proposals by Bartes (2013) and Gilad (2016) can be considered diagnostic examples, with the potential to be applied in the pre-adoption phase, and emphasize organizational readiness to receive the intelligence process. However, none of these models encompass all the conditions listed in the literature, which may leave gaps in the evaluation of some issues considered relevant.

\section{Methodology}

Exploratory research was conducted through a sequence of three qualitative methods to understand which conditions should be investigated in the pre-adoption phase of a structured intelligence process. The first qualitative method was a content analysis, conducted on the theoretical-conceptual reference of this research and on the diagnostic models raised in order to identify the presence or absence of a given content or a set of characteristics in a given content. Considering the steps of content analysis proposed by Bardin (1994) - overview on data, data categorization and grouping, and finally treatment of the obtained results - it was possible to interpret and make propositions according to the previously formulated goal of identifying the conditions involved in the pre-adoption stage of the intelligence process that must be evaluated through a diagnostic tool.

In the second step of the analysis, such conditions were validated by applying a card-sorting technique, a qualitative and iterative process that indicates the reliability of constructs through relationships confirmed by the participants (Nahm, Rao, Solis-Gavan, \& Ragu-Natan, 2002). Through the online platform OptimalSort, cards were presented with information already labeled in a numbered list with the main conditions (ORG - organizational, IND - individual, INF informational, TCM - technological/material, SIP - structured intelligence process), so that they could be matched with another list with the descriptions (Table 3). The participants - eight intelligence experts, including postgraduate students and field professionals - were invited to make combinations through cards (conditions) and descriptions. The results were analyzed and compared (Table 3) in order to identify a pattern of similarities among the responses and also to validate the conditions with the given descriptions (Faria, 2010).

Finally, in last step of the analysis, 30 professionals from the intelligence field (Table 4) were consulted and two rounds of Delphi technique were conducted in order to reach to a final set of conditions (Table 5) that they believe must be investigated before the adoption of a structured intelligence process and whose evaluation can indicate higher possibility of success and activity sustainability in organizations. Each round took up two weeks (March/April 2018), when the same participants were requested to review their positions and re-fill the questionnaire from the feedback received.

Twenty-eight statements composed the instrument of the Delphi rounds with a broad description of the pre-adoption conditions validated in the previous step of card sorting. The affirmations were given with an agreement Likert scale ranging from 1 to 5 points. For each block of statements,

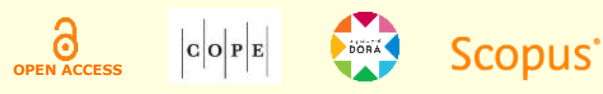


respondents had the opportunity to comment on their individual experiences about the given condition. In the second round of Delphi, only the statements that did not reach $80 \%$ of agreement in the first round (Hsu \& Sandford, 2007) were reevaluated by respondents, but at this time they were followed by the main arguments and experiences shared by the group in the first round.

The definition given by Delphi respondents considered their experience and involvement with the subject under investigation (Hsu \& Sandford, 2007; Wright, Silva, \& Spers, 2010). The respondent's identities were kept anonymous during the rounds, so that there was no influence of opinion among the members of the group. Thirty professionals were invited through social networks (LinkedIn and Facebook), among managers and senior analysts from Brazilian companies (technology, pharmaceuticals, financial institution, education, logistics, market research, hospital and public sector) with structured areas of intelligence, intelligence consultants, professors and students with a focus on intelligence studies (Table 4).

\section{Results}

The content analysis was determinant to building a framework (Table 2) of the conditions that must be evaluated before a structured intelligence process is adopted. From this first analysis, we identified organizational, individual, informational and technological/material conditions. Regarding the organizational reality, the pre-adoption conditions identified were related to strategic planning, organizational culture, planning and knowledge about the task, team support, senior management engagement and leadership involvement in the intelligence process. Individual conditions were linked to personal abilities, such as information sharing, engagement, specific profile and skills to properly conduct the intelligence activity. The informational conditions were related to scanning needs, environmental anticipation and external and internal management of the volume of information about the organization. Finally, pre-adoption conditions linked to technological and material issues involved the preliminary understanding of the infrastructure and time required for intelligence tasks.

Table 2

Pre-adoption framework of the structured intelligence process

\begin{tabular}{|c|c|c|}
\hline \multicolumn{3}{|c|}{ Organizational conditions } \\
\hline \multicolumn{2}{|c|}{ Elements to be evaluated } & Literature \\
\hline 1) Strategy & The intelligence process should be part of the organization strategic planning & \multirow{3}{*}{$\begin{array}{l}\text { Gilad and Gilad (1985); Choo (2003); } \\
\text { Marchand and Hykes (2007); Xu and } \\
\text { Kaye (2009); Bartes (2013); N. Lesca } \\
\text { et al. (2015); Luzipo, Van Biljon and } \\
\text { Herselman (2015); Janissek-Muniz } \\
\text { (2016); Jaharuddin, Dato'Mansor and } \\
\text { Yaakob (2016); Almeida et al. (2016); } \\
\text { Almeida and Hirata (2016). }\end{array}$} \\
\hline 2) Culture & $\begin{array}{l}\text { Information-driven culture stimulates the innovation process, market } \\
\text { differentiation and increase competitiveness. }\end{array}$ & \\
\hline 3) Planning & $\begin{array}{l}\text { The intelligence process must consider objectives, definitions and resources } \\
\text { limitations. }\end{array}$ & \\
\hline
\end{tabular}

Continues

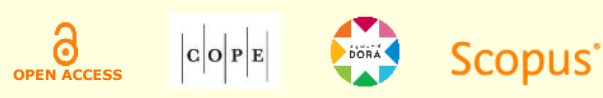




\section{Table 2 (continued)}

\section{Organizational conditions}

\section{Elements to be evaluated}

Literature

\begin{tabular}{|c|c|c|}
\hline $\begin{array}{l}\text { 4) Support and } \\
\text { commitment }\end{array}$ & $\begin{array}{l}\text { Support from top management, training, and user commitment are predictors } \\
\text { of the intelligence process adoption. }\end{array}$ & $\begin{array}{l}\text { Gilad and Gilad (1985); Choo (2003); } \\
\text { Marchand and Hykes (2007); Xu and }\end{array}$ \\
\hline 5) Leadership & $\begin{array}{l}\text { The organization must legitimize a leader or a committee responsible for } \\
\text { conducting the implementation of the intelligence process. }\end{array}$ & $\begin{array}{l}\text { et al. (2015); Luzipo, Van Biljon and } \\
\text { Herselman (2015); Janissek-Muniz } \\
\text { (2016); Jaharuddin, Dato'Mansor and } \\
\text { Yaakob (2016); Almeida et al. (2016); } \\
\text { Almeida and Hirata (2016). }\end{array}$ \\
\hline
\end{tabular}

Individual conditions

Elements to be evaluated

Literature

\begin{tabular}{|c|c|c|}
\hline 1) Sharing & $\begin{array}{l}\text { The sharing of knowledge among people within the company should be a } \\
\text { feature of the structured intelligence process to encourage diversity of } \\
\text { interpretation and vision of the future. }\end{array}$ & \multirow{2}{*}{$\begin{array}{l}\text { Gilad and Gilad (1985); Choo (2003); } \\
\text { Marchand and Hykes (2007); N. } \\
\text { Lesca and Caron-Fasan (2008); Xu } \\
\text { and Kaye (2009); Jalaldeen, Karin } \\
\text { and Mohamed (2009); Mayer (2012), } \\
\text { Bartes (2013); N. Lesca et al. (2015); } \\
\text { Janissek-Muniz (2016); Borges and } \\
\text { Janissek-Muniz (2017). }\end{array}$} \\
\hline 2) Profile & $\begin{array}{l}\text { An adequate personal profile and specific skills are needed for the } \\
\text { implementation and conduction of the intelligence process. }\end{array}$ & \\
\hline
\end{tabular}

Informational Conditions

Elements to be evaluated

Literature

\begin{tabular}{ll}
\hline 1) Anticipation & $\begin{array}{l}\text { The need for intelligence processes can be related to the need for exploring } \\
\text { the environment proactively, allowing the organization to address imminent } \\
\text { dangers or possible opportunities. }\end{array}$ \\
\hline 2) Scanning & $\begin{array}{l}\text { The need for intelligence processes can be related to understanding the } \\
\text { environment, solving a specific problem, or timely information for decision } \\
\text { making. }\end{array}$ \\
\hline 3) Dissemination & $\begin{array}{l}\text { Inadequate dissemination structure and planning can impoverish the } \\
\text { circulation of intelligence products and reduce confidence in the process. }\end{array}$ \\
\hline 4) Volume & $\begin{array}{l}\text { The information volume currently available is one of the most relevant issues } \\
\text { about the need to implement intelligence processes. }\end{array}$
\end{tabular}

\section{Technological and material conditions}

Elements to be evaluated

Literature

H. Lesca (2003); Janissek-Muniz (2004); Marchand and Hykes (2007); Brouard (2007); N. Lesca and CaronFasan (2008); N. Lesca et al. (2015); Gilad (2016); Janissek-Muniz (2016); Soliman and Karia (2017).
1) Infrastructure

Technological solutions are relevant and can enhance the ability to appropriately manage information flows.

2) Time
Strategic information should arrive at the appropriate time for decisionmaking.
Baumard (1997); Marchand et al. (2001); Belmondo (2008); Calof and Wright (2008); Bartes (2013); Rios and Janissek-Muniz (2014); N. Lesca et al. (2015); Janissek-Muniz (2016). 
Card sorting was conducted to validate the conditions and elements identified in this framework and the inherent conditions of the structured intelligence process (SIP). The respondents had to organize the cards in a way that, in their opinion, made up the same set. The agreement rate was calculated, and the results were classified according to the Kappa coefficient (Nahm et al., 2002), as shown in Table 3.

Table 3

\section{Card sorting results}

\begin{tabular}{|c|c|c|}
\hline Conditions and elements & Agreement rate & Kappa coefficient \\
\hline ORG (Culture) & $89 \%$ & \multirow{8}{*}{ - Excellent (percentage agreement higher than $76 \%$ ) } \\
\hline ORG (Planning) & $78 \%$ & \\
\hline IND (Individual knowledge) & $78 \%$ & \\
\hline INF (Anticipation) & $78 \%$ & \\
\hline INF (Volume) & $78 \%$ & \\
\hline TCM (Infrastructure) & $89 \%$ & \\
\hline SIP (Arrangement) & $78 \%$ & \\
\hline SIP (Continuity) & $89 \%$ & \\
\hline ORG (Strategy) & $67 \%$ & \multirow{9}{*}{ Moderate (percentage agreement between $75 \%$ and $40 \%$ ) } \\
\hline ORG (Support and commitment) & $56 \%$ & \\
\hline ORG (Leadership) & $67 \%$ & \\
\hline IND (Sharing) & $56 \%$ & \\
\hline IND (Profile) & $56 \%$ & \\
\hline INF (Scanning) & $67 \%$ & \\
\hline INF (Dissemination) & $67 \%$ & \\
\hline TCM (Time) & $44 \%$ & \\
\hline SIP (Formalization) & $67 \%$ & \\
\hline
\end{tabular}

- $\quad$ - Poor (percentage agreement lower than 39\%)

After evaluating the results, conditions with excellent Kappa coefficient validated the proposed element descriptions. Conditions with moderate Kappa coefficient showed ambiguous relations, indicating that these elements descriptions should be reformulated to improve the understanding of them. After refining the descriptions, a list of statements (Table 5) was organized to compose the instrument of the next data collection step, the Delphi questionnaire (Appendix). 
Overall, 30 professionals answered the first and second round of the Delphi, as described in Table 4. Wright, Silva, and Spers (2010) have indicated that a number between 15 and 30 respondents is representative, enough to generate relevant information.

Table 4

\section{Delphi respondentes}

\begin{tabular}{ll}
\hline Occupation & Number of participants \\
\hline ClO or manager & 8 \\
\hline Intelligence freelancer or consultant & 7 \\
\hline Intelligence senior analyst & 7 \\
\hline Intelligence graduate student & 5 \\
\hline Intelligence researcher or professor & 3 \\
\hline
\end{tabular}

Regarding the organizational pre-adoption conditions, the most important information pointed out by respondents is defining process objectives in advance. They also believe that when the intelligence area or function is considered part of the organization's strategic planning, the activity is enhanced, which is an essential factor to be considered before its implementation. On the other hand, respondents recognize that in practice, the first results produced from the area justify and strengthen its strategic aspect, especially for higher hierarchical managers, recognized as the great beneficiaries of the activity. As to organizational structure, the decentralized model seems to make sense for the participants: more important than having a specific area, is to stipulate beforehand who will be involved in the process and which will be the roles and responsibilities of each one. Although they recognize that it is important to have a specific budget for the activity, some respondents highlighted the fact that the process can start just with available data, but it is relevant to be aware of costs for demands that may show up over time. Another condition mentioned is the information-driven culture, which facilitates the conduction of the process, but is not a determining factor before its adoption. However, it was recognized that when information has strategic value within the organization, the intelligence process is more likely to be adopted. Regarding the people involved in the process - recognized by participants as core agents for its progress - they must have as their main attributions to promote, develop, and reinforce the intelligence culture within the company. In this sense, it is desirable to appoint a committee, a team or a workgroup of people in charge, who are aligned and motivated to promote it in the company, without necessarily initiating the process. The respondents' practical experience indicates that the initial commitment of top management and leaders is instead a fundamental point to initiate the intelligence process in organizations and to raise awareness about its relevance.

Concerning the individual pre-adoption conditions, respondents recognize some fundamental characteristics related to the person's profile involved in intelligence activities that may affect process success. Some skills, such as motivation and curiosity to learn, the spirit of sharing and

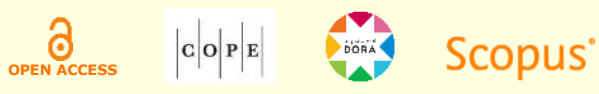


analytical ability, stood out much more than a specific need for technical training to perform the activity. It is worth mentioning that some respondents recognize that specific training on intelligence topics should be a professional prerequisite, since the absence of this knowledge may cause gaps in the process. However, they admit that the shortage of educational courses related to intelligence in Brazil is one of the main reasons why the activity is learned from practice. Regarding the channels for obtaining information, informal sources - composed of personal relationships - seem to be essential and complementary to formal sources of intelligence and can generate insights for future ideas.

It is crucial for the intelligence professional to have the ability to go through informal conversations, form networks, and exchange experiences to extract pertinent information when necessary. Considering the individual behavior inside organizational staff, it is important to reinforce how company employees can also collaborate for the intelligence process in order to build trust and synergy in information exchange. This awareness can be built over time, when the process is already installed. As deliveries are made, the internal contribution with the intelligence area enhances. For respondents, consciousness, knowledge, and willingness to adopt the process are important, but not decisive in the stage that precedes the implementation of the structured intelligence process.

Pre-adoption conditions related to technology had the lowest degree of agreement among specialists. Apparently, it would be possible to succeed in the intelligence area with a basic technological infrastructure, which includes a good computer, internet access and Microsoft Office applications, for example. Depending on the monitoring scope and the human resources available, outsourced services may be necessary, mainly to accelerate data collection and to reduce engagement in operational steps, in order to prioritize the analysis step, which requires higher human performance. These considerations are more related to the conduction of the intelligence process than elements that should be evaluated in the pre-adoption phase. The prior definition of the time required for each stage of the intelligence process was considered important, but not decisive for process adoption, as many other factors influence this variable, such as availability, scope, and resources. Respondents admit that before defining these three issues, it may be interesting to run a complete intelligence cycle to have a more realistic perception of the time required for each step of the process. On the other hand, one of the respondents emphasizes that temporal planning is fundamental, so that the sense of opportunity is not lost while the intelligence process is being executed.

The respondents' understanding of pre-adoption conditions related to the structured intelligence process is evident. With excellent results in the first round of Delphi, there is a high agreement that ideally the activity must be continuous, formalized and organized to be considered a structured process. However, in general, practitioners recognize that the intelligence process is conducted in a discontinuous or disorganized way (organizations only perform part of the process), and they understand that it is necessary to disseminate concepts to enhance the continuity and sustainability of the process within the organization. Corroborating this idea, the respondents argue that monitoring routine should be systematic, as it allows the identification of problems and opportunities while maintaining the anticipatory focus and the recognition of weak

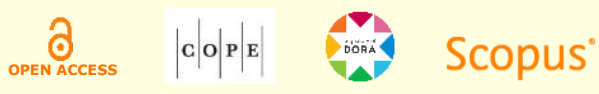


signals in the environment. In their perspective, it means that the lack of continuity in the intelligence activity may imply significant informational losses, since the high frequency of ad hoc requests, or unplanned tasks, weakens the continuity of the strategic scanning if it happens too often. It is true that some situations require punctual glances and specific depth, much more tactical than strategic. However, the participants agreed that this should not be the main activity of intelligence, as it generates disorganization and inefficiency in the process, reducing the strategic nature and analytical capacity of the area.

To summarize the results, Table 5 presents the agreement scores about the statements given to the participants in the questionnaire of the two Delphi rounds.

Table 5

\section{Agreement of the conditions investigated}

\begin{tabular}{|c|c|c|c|}
\hline Questionnaire statements & $\begin{array}{c}\text { 1st } \\
\text { Delphi }\end{array}$ & $\begin{array}{l}\text { 2nd } \\
\text { Delphi }\end{array}$ & $\begin{array}{l}\text { Agree- } \\
\text { ment }\end{array}$ \\
\hline $\begin{array}{l}\text { ORG (Strategy) - Before adopting a structured intelligence process, the organization must } \\
\text { consider it as an important part of its strategic planning. }\end{array}$ & $88 \%$ & - & YES \\
\hline $\begin{array}{l}\text { ORG (Culture) - Before adopting a structured intelligence process, the organization must have } \\
\text { an information-driven organizational culture. }\end{array}$ & $73 \%$ & $72 \%$ & NO \\
\hline $\begin{array}{l}\text { ORG (Planning) - The adoption of the structured intelligence process requires a prior definition } \\
\text { of objectives. }\end{array}$ & $85 \%$ & - & YES \\
\hline $\begin{array}{l}\text { ORG (Support) - The adoption of the structured intelligence process requires a prior definition } \\
\text { of the organizational structure that will be involved in it. }\end{array}$ & $75 \%$ & $91 \%$ & YES \\
\hline $\begin{array}{l}\text { ORG (Support) - The adoption of the structured intelligence process requires a prior definition } \\
\text { of the financial resources that will be spent in its execution. }\end{array}$ & $69 \%$ & $59 \%$ & NO \\
\hline $\begin{array}{l}\text { ORG (Commitment) - Before adopting a structured intelligence process, the organization must } \\
\text { establish a committee, team or working group of people in charge, aligned and motivated to } \\
\text { carry out the process in the organization. }\end{array}$ & $61 \%$ & $78 \%$ & NO \\
\hline $\begin{array}{l}\text { ORG (Support) - Prior top management support is decisive for the adoption of a structured } \\
\text { intelligence process. }\end{array}$ & $97 \%$ & - & YES \\
\hline $\begin{array}{l}\text { ORG (Leadership) - The structured intelligence process must define, in advance, leaders } \\
\text { designated and legitimized by the organization. }\end{array}$ & $90 \%$ & - & YES \\
\hline $\begin{array}{l}\text { IND (Sharing) - The sharing of knowledge is an essential personal skill of the intelligence } \\
\text { professional. }\end{array}$ & $90 \%$ & - & YES \\
\hline $\begin{array}{l}\text { IND (Profile) - Owning and using informal or individual channels is an essential personal skill of } \\
\text { the intelligence professional. }\end{array}$ & $76 \%$ & $86 \%$ & YES \\
\hline $\begin{array}{l}\text { IND (Profile) - Motivation to learn about relevant business environments is an essential } \\
\text { personal skill of the intelligence professional. }\end{array}$ & $96 \%$ & - & YES \\
\hline $\begin{array}{l}\text { IND (Profile) - Specialized technical education is an essential prerequisite for hiring intelligence } \\
\text { professionals. }\end{array}$ & $56 \%$ & $57 \%$ & NO \\
\hline
\end{tabular}




\section{Table 5 (continued)}

\begin{tabular}{|c|c|c|c|}
\hline Questionnaire statements & $\begin{array}{c}\text { 1st } \\
\text { Delphi }\end{array}$ & $\begin{array}{l}\text { 2nd } \\
\text { Delphi }\end{array}$ & $\begin{array}{c}\text { Agree- } \\
\text { ment }\end{array}$ \\
\hline $\begin{array}{l}\text { IND (Knowledge) - Employees must be previously aware that the organization will adopt a } \\
\text { structured intelligence process. }\end{array}$ & $68 \%$ & $71 \%$ & NO \\
\hline $\begin{array}{l}\text { IND (Knowledge) - Employees must know what a structured intelligence process is before its } \\
\text { adoption by the organization. }\end{array}$ & $52 \%$ & $62 \%$ & NO \\
\hline $\begin{array}{l}\text { IND (Knowledge) - Employees must be willing to adopt a structured intelligence process before } \\
\text { its adoption by the organization. }\end{array}$ & $58 \%$ & $77 \%$ & NO \\
\hline $\begin{array}{l}\text { IND (Knowledge) - Employees must recognize the relevance of a structured intelligence } \\
\text { process before its adoption by the organization. }\end{array}$ & $61 \%$ & $83 \%$ & YES \\
\hline $\begin{array}{l}\text { INF (Scanning) - A prior need for exploring external informational flows is fundamental in order } \\
\text { to adopt a structured intelligence process. }\end{array}$ & $93 \%$ & - & YES \\
\hline $\begin{array}{l}\text { INF (Anticipation) - A prior need of proactively exploring the environment (in order to anticipate } \\
\text { opportunities and imminent risks) is fundamental in order to adopt a structured intelligence } \\
\text { process. }\end{array}$ & $88 \%$ & - & YES \\
\hline $\begin{array}{l}\text { INF (Dissemination) - E-mails, reports, and dashboards are enough as structures for } \\
\text { intelligence dissemination. }\end{array}$ & $34 \%$ & $43 \%$ & NO \\
\hline $\begin{array}{l}\text { INF (Volume) - The volume, variety, and speed of information currently available (Big Data) } \\
\text { influence the adoption of a structured intelligence process. }\end{array}$ & $64 \%$ & $48 \%$ & NO \\
\hline $\begin{array}{l}\text { TCM (Infrastructure) - It is necessary to provide specific platforms and tools before adopting a } \\
\text { structured intelligence process. }\end{array}$ & $36 \%$ & $34 \%$ & NO \\
\hline $\begin{array}{l}\text { TCM (Infrastructure) - Before adopting a structured intelligence process, the organization must } \\
\text { hire outsourced information gathering services. }\end{array}$ & $34 \%$ & $24 \%$ & NO \\
\hline $\begin{array}{l}\text { TCM (Infrastructure) - Before adopting a structured intelligence process, the organization must } \\
\text { provide technological infrastructure support. }\end{array}$ & $36 \%$ & $29 \%$ & NO \\
\hline $\begin{array}{l}\text { TCM (Time) - Before adopting a structured intelligence process, the organization must define } \\
\text { the appropriate time for each stage of the process (planning / collection / analysis / } \\
\text { dissemination / evaluation). }\end{array}$ & $51 \%$ & $43 \%$ & NO \\
\hline SIP (Continuity) - The structured intelligence process should be an ongoing task. & $97 \%$ & - & YES \\
\hline $\begin{array}{l}\text { SIP (Continuity) - The structured intelligence process should NOT be conducted with ad hoc } \\
\text { requests most of the time. }\end{array}$ & $56 \%$ & $81 \%$ & YES \\
\hline $\begin{array}{l}\text { SIP (Arrangement) - The structured intelligence process must fulfill a set of well-defined steps } \\
\text { (planning / collection / analysis / dissemination / evaluation). }\end{array}$ & $93 \%$ & - & YES \\
\hline $\begin{array}{l}\text { SIP (Formalization) - The structured intelligence process must have routines of problem } \\
\text { recognition and opportunity monitoring. }\end{array}$ & $85 \%$ & - & YES \\
\hline
\end{tabular}

In summary, given the agreement rates from Delphi rounds, a range of questions was proposed to the pre-adoption diagnosis in order to evaluate conditions before the intelligence process is adopted in organizations. Data is arranged sequentially in a list presented in Table 6 to answer this research's objective. 
Table 6

Pre-adoption diagnostic script of the structured intelligence process

Conditions
$\begin{aligned} & \text { Questions } \\ & \text { Does the organization consider adopting a structured intelligence process as part of its strategic } \\ & \text { planning? }\end{aligned}$
Does the organization's senior management support the adoption of a structured intelligence
process?
- Do the organization's main leaders support the adoption of a structured intelligence process?
- Do key decision-makers want to make decisions based on the intelligence produced?
- Is the organization aware of the goals it wants to achieve by adopting a structured intelligence
- Have intelligence activities been already defined?
- Istl intelligence activity be centralized (with an intelligence area) or decentralized (with people in
charge of intelligence activities in other areas of the organization)?
- Is there a person designated as the intelligence process leader, responsible for conducting the
implementation of the intelligence process?

- Does the person who is going to take over the intelligence role or activity have skills like motivation and curiosity to learn, information sharing and analytical ability?

- Does the person who is going to take over the intelligence role or activity have relational skills to transit through informal conversations to form networks and exchange experiences?

Individual

- Do people in the organization understand the relevance of a structured intelligence process?

- Do people in the organization understand that their contribution to obtaining, sharing, and analyzing information matters?

- Does the organization recognize that there is a necessity to explore information flows from the organization's external environment?

- Does the organization want to monitor the external environment to identify threats in an anticipatory way?

Informational

- Is there any information or target map (with actors and themes) that need to be monitored?

- Is there a plan of how the intelligence dissemination will be organized, relating formats, contents, channels, and receivers?

- Is there a plan of how the information related to the intelligence process will be managed?

- Do the organization and the people involved understand the relevance of a structured intelligence process?

- Do the organization and the people involved understand the importance of the continuity of the intelligence activities?

Structured intelligence process

- Do the organization and people involved understand that the high frequency of ad hoc demands can reduce the strategic objective of the intelligence process?

- Do the organization and the people involved understand the importance of completing all stages of a structured intelligence process (planning, gathering, analysis, dissemination, evaluation)?

- Do the organization and the people involved understand that the structured intelligence process must include monitoring routines for systematic recognition of problems and opportunities that emerge from the external environment? 
Using the suggested diagnostic script, organizations are expected to explore the organizational and human conditions that allow the recognition of strengths and weaknesses to accomplish the intelligence process, aiming at structuring or implementing it. When applied with open-ended questions as a base to a small sample of employees and decision-makers from the same company, the questionnaire provides more significant insights into the challenges that need to be overcome and improved to achieve the goal of setting a structured intelligence process. When applied quantitatively, for a larger sample of people from the same organization, the result of the proposed questionnaire allows generating indicators that can be periodically evaluated in a survey application. In both ways, the objective will be reached, since it will allow mapping, to a greater or lesser extent, the issues that require attention, discussion and/or definition of actions for implementation or better structuring of the intelligence process.

\section{Discussion}

Due to the scarcity of evaluative models present in the literature and the relevance of this previous step pointed by some authors (Brouard, 2007; Gilad, 2016; Herring, 1999; H. Lesca, 2003; Iden et al., 2017; Janissek-Muniz, 2016; N. Lesca et al., 2015), it was necessary to seek guidance from experts and professionals in the intelligence market in order to gain a working knowledge of the relevant conditions that organizations need to consider before adopting a structured intelligence process. Given the conditions found in this review, the opinion of practitioners (thirty professionals from intelligence areas of several industries in Brazil) was exploited in the two rounds of Delphi to validate the literature findings and to understand what should be evaluated before the intelligence process is adopted in organizations and what motivates companies to start it. Employing Delphi in this study has allowed an enriching approach to capture ideas from a group of experts and researchers with high knowledge and experience in the organizational intelligence field.

Organizational pre-adoption conditions had the highest agreement rates among respondents. As Luzipo et al. (2015) point out, the support of top management is a strong predictor for the adoption of a process, and this factor is also specifically highlighted for the structured intelligence process. Since the key decision-makers in an organization understand the strategic value that the activity can generate, they provide the necessary support for its set-up and continuity. Therefore, there must be, a priori, the desire of the organization and the top management to make decisions based on information, collected and interpreted from a structured intelligence process. Likewise, the prior choice of a leader for the intelligence process, referred to as an "animator" by H. Lesca (2003, p. 21) and Janissek-Muniz (2016), is recognized as a central player in the stage that precedes the adoption. This person is responsible for motivating and sensitizing employees on the relevance of the process, promoting the organizational culture focused on sharing information, defining those responsible for the routines, identifying the informational needs and planning the organization's intelligence activities.

In turn, conditions that involve individual pre-adoption conditions became more evident when related to specific skills of the people who were conducting the intelligence process. In this sense, the main contribution of this research was a list of characteristics that should be previously

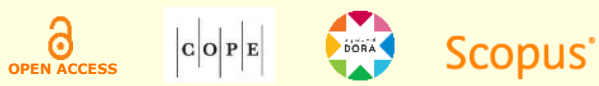


recognized in the human resources involved in the activity. It doesn't mean that all characteristics must be found in one single person, but these skills must be considered when building and developing an intelligence team. It can be considered kind of anticipative preparation, as mentioned by Bartes (2013), when it is necessary to review the qualification of the team working on intelligence projects, such as cognitive style, curiosity and capacity of sharing and gathering information from formal or informal sources, as mentioned by the respondents of this research.

When exploring the informational pre-adoption conditions, the need to manage the external information flows emerges as a strong influence on the decision to institute an intelligence process. The individual awareness of the leaders and the employees' comprehension that it is possible to identify opportunities and threats that arise in the external environment must be diagnosed among key decision-makers and future consumers of the intelligence that will be produced. This is crucial to produce value-added information and support strategic decisions, key issues to maintaining a sustainable competitive advantage, as mentioned by Choo (1999) and Tarapanoff (2006).

The need for technological infrastructure does not appear as a determining condition before the adoption of the intelligence process, but once it is already implemented, platforms and software can be relevant as the information management needs arise. In this sense, Big Data is recognized as an additional source of information that needs to be managed and mined by technology to help build the intelligence deliveries. Temporal planning for the intelligence activity was not identified as a predictor condition to be evaluated since this can be adjusted as the cycles are performed.

Despite the strong comprehension among respondents about what a structured intelligence process should be (recognized by them as a continuous, organized and formalized process), unplanned requests for information gathering still permeate company reality and may undermine the strategic performance of the area. The intelligence process is acknowledged to be dynamic, and unplanned requests may occur, but there must be internal awareness of how much strategic information is lost when the activity is conducted in an unstructured and discontinuous way through frequent ad hoc deliveries.

Given that disorganized intelligence practices are still acknowledged in companies (Borges \& Janissek-Muniz, 2017), the evaluation of the suggested conditions in the proposed diagnostic script can help to plan the adoption of the intelligence process, to raise awareness of the people involved or to improve the conduction of activities which are already in progress. It is important to emphasize that, as pointed out by the respondents, the intelligence process is often implemented without prior planning and that the evaluation of these conditions could enhance the activity adoption and conduction by indicating the necessary adjustments. This anticipative evaluation is an excellent indicator of the needs to reach maturity in the intelligence process and is a great predictor of the future success of the activity. In fact, this evaluation enables the organization to improve organizational and individual capabilities in order to perform better, since it allows designing structures and processes that direct the firm towards continuous improvement, innovation and change (Marino, 1996).

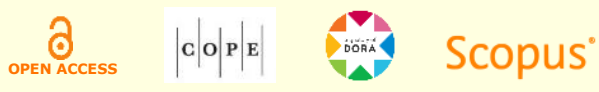




\section{Conclusions}

The elements of the intelligence process identified in the Information Systems literature review, in the Strategic Intelligence literature perspective and in the intelligence diagnostic models raised in this work provided the theoretical background to compose a pre-adoption framework for the structured intelligence process, since much of the literature does not focus on identifying what motivates the adoption of a structured intelligence process (Iden et al., 2017; N. Lesca et al., 2015).

In fact, rare are the authors who have bothered to investigate this previous step in depth, to understand what are the external and internal conditions that motivate the adoption of the intelligence process. Most papers found in literature deal with issues related to use, methods and outcomes, as contributions of the process (Iden et al., 2017). Still, when looking at the few evaluative models found in the literature, it is clear that most of them deal with issues related to the practice of the intelligence process, but not specifically to the previous stage, when human and organizational conditions need to be evaluated and provided in order to enhance the chances of success of the activity in the future (Gilad, 2016). Moreover, and because models are mostly practice-based, their construction lacks the theoretical support or basis underlying the structuring of instruments based on scientific research results.

In general, the proposed diagnostic script fills a theoretical gap by presenting a consolidated tool that encompasses all the conditions raised in this study. The questions allow mapping organizational and individual issues that can be developed to increase the chances of success and maintenance of the intelligence activity and indicate improvements to be made and opportunities to explore in the area. After all, the more structured the intelligence process is, the more it can generate competitive advantage for organizations (N. Lesca \& Caron-Fasan, 2008).

It is also important to highlight that the objective of this work was not to discuss ways to measure the results generated by the questionnaire, but even so, some qualitative and quantitative paths were pointed out. This discussion deserves deepening in future research, as well as the application of the questionnaire in specific industry segments to identify complements and even inadequacies regarding questions.

Another suggestion is to evaluate the impact of each variable of the proposed pre-adoption framework to understand which condition has the most significant impact on the structuring of the intelligence process. It is also understood as a limitation of the study, that many issues were evaluated at the same time through Delphi rounds. Despite having good adherence, another point that can be considered as a limitation is that the questionnaire was quite long and some participants failed to give opinions due to the time it took to answer it. Further, evaluating each of the conditions in separate surveys would provide more productive and more specific accounts. In addition, a larger number of respondents and a broader field of industries could further enrich shared experiences.

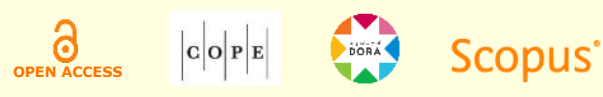


Also, considering the lack of evaluative models in the specific intelligence literature, other diagnostic tools, from other areas of knowledge, can be used to compose new investigative approaches. From another point of view, it is also recommended that studies using the diagnostic models mentioned in this research can be analyzed to understand how these tools were applied and what results and complementary discussions they generated.

\section{References}

Aguilar, F. J. (1967). Scanning the business environment. New York, NY: MacMillan.

Almeida, F. C. de, \& Hirata, P. (2016). Entendendo e implantando um sistema de inteligência competitiva. Revista de Gestão, 23(2), 111-122. https://doi.org/10.1016/j.rege.2014.12.001

Almeida, F. C. de, Lesca, H., \& Canton, A. W. P. (2016). Intrinsic motivation for knowledge sharing - Competitive intelligence process in a telecom company. Journal of Knowledge Management, 20(6), 1282-1301. https://doi.org/10.1108/jkm-02-2016-0083

Andriotti, F. K., Freitas, H., \& Janissek-Muniz, R. (2008). Informação informal e a monitoração do ambiente organizacional: Reflexões e sugestões para a área de TI. Anais do Prêmio de Inovação em Inteligência Competitiva ABRAIC, Brasilia, DF, Brazil, 3.

Bardin, I. (1994). Análise de conteúdo. Lisboa, Portugal: Edições Setenta.

Bartes, F. (2013). The process of implementing competitive intelligence in a company. Acta Universitatis Agriculturae et Silviculturae Mendelianae Brunensis, 61(4), 861-866. https://doi.org/10.11118/actaun201361040861

Baumard, P. (1997). L'information stratégique dans la grande organisation. Systèmes d'Information et Management [French Journal of Management Information Systems], 2(2), 5-29. http://dx.doi.org/10.9876/sim.v2i2.24

Belmondo, C. (2008). Comprendre les pratiques des acteurs de l'intelligence économique: Une étude des microactivités de représentation de l'environnement concurrentiel et d'organisation de la veille. Systèmes d'Information et Management, 13(3), 83-107. https://doi.org/10.3917/sim.083.0083

Borges, N. M., \& Janissek-Muniz, R. (2017). The environmental scanning as an informal and individual practice in organizations. A view based on the Illusion of Control's Theory. Annales des Congrès de l'Institut Franco Brésilien d'Administration des Entreprises, Poitiers, France, 9.

Brouard, F. (2007). Development of an expert system on environmental scanning practices in SME: Tools as a research program. Journal of Competitive Intelligence and Management, 3(4), 37-58.

Calof, J. L., \& Wright, S. (2008). Competitive intelligence: A practitioner, academic and inter-disciplinary perspective. European Journal of Marketing, 42(7/8), 717-730. https://doi.org/10.1108/03090560810877114

Caron-Fasan, M.-L., \& Janissek-Muniz, R. (2002). Pérennisation de l'intelligence collective anticipative. Colloque AIM, Hammamet, Tunisie, 7.

Casagrande, A., Aguirre, E. L., \& Vuillon, L. (2015, April). Improving strategic scanning information analysis: An alternative measure for information proximity evaluation. International Conference on Enterprise Systems (ES), Basel, Switzerland, 17.

Choo, C. W. (1999). The art of scanning the environment. Bulletin of the American Society for Information Science and Technology, 25(3), 21-24. https://doi.org/10.1002/bult.117

Choo, C. W. (2001). Environmental scanning as information seeking and organizational learning. Information Research, 7(1), 7-1.

Choo, C. W. (2003). A organização do conhecimento: Como as organizações usam a informação para criar significado, construir conhecimento e tomar decisões. São Paulo, Brazil: Senac São Paulo.

Daft, R. L., \& Weick, K. E. (1984). Toward a model of organizations as interpretation systems. Academy of Management Review, 9(2), 284-295. https://doi.org/10.5465/amr.1984.4277657

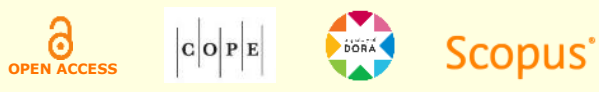


Davenport, T. H., Harris, J. G., \& Morison, R. (2010). Analytics at work: Smarter decisions, better results. Boston, MA: Harvard Business School Press.

Davis, J. R. (2008). Does environmental scanning by systems integration firms improve their business development performance? Largo, MD: University of Maryland University College.

Fachinelli, A. C., Giacomello, C. P., Rech, J., \& Bertolini, A. L. (2013). Inteligência estratégica: Desenvolvimento de uma escala para a compreensão do construto. Revista Brasileira de Estratégia, 6(2), 179-191. https://doi.org/10.7213/rebrae.06.002.ao06

Faria, M. M. de. (2010). Card sorting: Noções sobre a técnica para teste e desenvolvimento de categorizações e vocabulários. Revista Digital de Biblioteconomia e Ciência da Informação, $7(2), \quad 1-9$. https://doi.org/10.20396/rdbci.v7i2.1953

Gilad, B. (2016, February). Developing competitive intelligence capability. Retrieved from https://www.imanet.org/insights-and-trends/technology-enablement/developing-competitive-intelligencecapability?ssopc $=1$

Gilad, B., \& Fuld, L. M. (2016, January). Only half companies actually use the competitive intelligence they collect. Harvard Business Review. Retrieved from https://hbr.org/2016/01/only-half-of-companies-actually-use-thecompetitive-intelligence-they-collect

Gilad, B., \& Gilad, T. (1985). A system approach to Business Intelligence. Business Horizons, 28(5), 65-70. https://doi.org/10.1016/0007-6813(85)90070-9

Hakansson, C., \& Nelke, M. (2015). Competitive intelligence for information professionals. Whaltham, MA: Chandos Publishing.

Herring, J. P. (1999). Key intelligence topics: A process to identify and define intelligence needs. Competitive Intelligence Review, 10(2), 4-14. https://doi.org/10.1002/(sici)1520-6386(199932)10:2\%3C4::aidcir3\%3E3.3.co;2-3

Hsu, C. C., \& Sandford, B. (2007). The delphi technique: Making sense of consensus. Practical Assessment, Research EE Evaluation, 12(10), 1-8. Retrieved from http://pareonline.net/pdf/v12n10.pdf

Iden, J., Methlie, L. B., \& Christensen, G. E. (2017). The nature of strategic foresight research: A systematic literature review. Technological Forecasting and Social Change, 116, 87-97. https://doi.org/10.1016/j.techfore.2016.11.002

Jaharuddin, N. S., Dato’Mansor, Z., \& Yaakob, S. (2016). Assessing the supply chain intelligence practices of small medium enterprises in Malaysia. Procedia Economics and Finance, 35, 515-521. https://doi.org/10.1016/s2212. 5671(16)00064-2

Jalaldeen, R., Karin, N. S. A., \& Mohamed, N. (2009). Organizational readiness and its contributing factors to adopt KM processes: A conceptual model. Communications of the IBIMA, 8, 128-136. Retrieved from https://pdfs.semanticscholar.org/3bf1/631e88a645b578b373bab2e92bc2dd3449b6.pdf

Janissek-Muniz, R. (2004). Veille anticipative stratégique en PMI: Vers un nouvel usage des sites web pour provoquer des informations 'terrain' afin d'amorcer des innovations; concepts, instrumentation et validation (Thèse de doctorat). Sciences de Gestion, Université Pierre Mendès, Grenoble, France.

Janissek-Muniz, R. (2016). Fatores críticos em projetos de inteligência estratégica antecipativa e coletiva. Revista Inteligência Competitiva, 6(2), 147-180. http://dx.doi.org/10.24883\%2Fric.v6i2.159

Kahaner, L. (1996). Competitive intelligence: How to gather, analyze, and use information to move your business to the top. New York, NY: Simon \& Schuster.

Lesca, H. (2003). Veille stratégique: La méthode LESCAnning®. Caen, France: Editions EMS Management et Société.

Lesca H., Cavalade, C., Darves, F., \& Deck, V. (1995). Fennec: A dashboard to evaluate environmental scanning within businesses (Etude CERAG 95-09). Retrieved from http://www.veille-strategique.org/docs/1995-lesca-fennec.pdf

Lesca, N., \& Caron-Fasan, M.-L. (2008). Strategic scanning project failure and abandonment factors: Lessons learned. European Journal of Information Systems, 17(4), 371-386. https://doi.org/10.1057/ejis.2008.21 
Lesca, N., Caron-Fasan, M.-L., Aguirre, E. L., \& Chalus-Sauvannet, M.-C. (2015). Drivers and barriers to preadoption of strategic scanning information systems in the context of sustainable supply chain. Systèmes d'Information EF Management, 20(3), 9-46. https://doi.org/10.3917/sim.153.0009

Luzipo, S., Van Biljon, J., \& Herselman, M. (2015, May). Business process adoption in organizations: A case study from an insurance company in South Africa. Proceedings of the IST-Africa Conference, Lilongwe Malawi.

Marchand, D., Kettinger, W., \& Rollins, J. (2001). Making the invisible visible: How companies win with the right information, people, and IT. London, UK: John Wiley \& Sons Ltd.

Marchand, D., \& Hykes, A. (2007). Leveraging what your company really knows: A process view of strategic intelligence. In M. Xu (Ed.), Managing strategic intelligence: Techniques and technologies (pp. 1-13). Hershey, PA: Information Science Reference.

Marino, K. E. (1996). Developing consensus on firm competencies and capabilities. The Academy of Management Executive, 10(3), 40-51. Retrieved from https://www.jstor.org/stable/4165337

Mayer, J. H. (2012, June). Powering up companies' crystal balls: Analysis of a multi-case study towards more applicable environmental scanning systems. Proceedings of European Conference on Information Systems (ECIS), Barcelona, Spain, 20.

Mayer, J. H., Steinecke, N., Quick, R., \& Weitzel, T. (2013). More applicable environmental scanning systems. Information Systems and E-business Management, 11(4), 507-540. https://doi.org/10.1007/s10257-012-0207-7

McGonagle, J. J., \& Vella, C. M. (2002). Bottom line competitive intelligence. Westport, CT: Greenwood Publishing Group.

Nahm, A. Y., Rao, S. S., Solis-Gavan, L. E., \& Ragu-Natan, T. S. (2002). The Q-Sort method: Assessing reliability and construct validity of questionnaire items at a pre-testing stage. Journal of Modern Applied Statistical Methods, 1(1), 114-125. https://doi.org/10.22237/jmasm/1020255360

Rios, F. L. de C., \& Janissek-Muniz, R. (2014). Uma proposta de relação de requisitos funcionais para um software de apoio ao processo de inteligência. Revista Eletrônica da Administração, 20(2), 425-460. https://doi.org/10.1590/1413-2311056201238165

Russo, R., Sbragia, R., \& Abraham, S. (2017). Unknown unknowns in innovative projects: Early signs sensemaking. Brazilian Administration Review, 14(3), e170060. https://doi.org/10.1590/1807-7692bar2017170060

Sassi, D. B., Frini, A., Abdessalem, W. B., \& Kraiem, N. (2015). Competitive intelligence: History, importance, objectives, process and issues. International Conference on Research Challenges in Information Science (RCIS), Athens, Greece, 9. https://doi.org/10.1109/rcis.2015.7128910

Soliman, M., \& Karia, N. (2017). Antecedents for the success of the adoption of organizational ERP among higher education institutions and competitive advantage in Egypt. Engineering, Technology \& Applied Science Research, 7(3), 1719-1724. Retrieved from https://www.etasr.com/index.php/ETASR/article/view/1113/507

Strategic and Competitive Intelligence Professionals. (2017). Competitive intelligence: A 10 year global development. CI Magazine, 20(2), 21-26. Retrieved from https://issuu.com/scippublications/docs/cim_summer_full_issue_pages/20

Tarapanoff, K. (2006). Inteligência, informação e conhecimento. Brasília, Brazil: IBICT.

Teece, D., Pisano, G., \& Shuen, A. (1997). Dynamic capabilities and strategic management. Strategic Management Journal, 18(7), 509-533. https://doi.org/10.1002/(sici)1097-0266(199708)18:7\%3C509::aidsmj882\%3E3.0.co;2-z

Tsoukas, H., \& Shepherd, J. (2004). Managing the future: foresight in the knowledge economy. Oxford, UK: Blackwell Publishing.

Verville, J., Bernadas, C., \& Halingten, A. (2005). So you're thinking of buying an ERP? Ten critical factors for successful acquisitions. Journal of Enterprise Information Management, 18(6), $665-677$. https://doi.org/10.1108/17410390510628373

Vidigal, F. (2013). Competitive intelligence: Functional practices, goals and infrastructure of companies in Brazil. Transinformação, 25(3), 237-243. https://doi.org/10.1590/s0103-37862013000300006

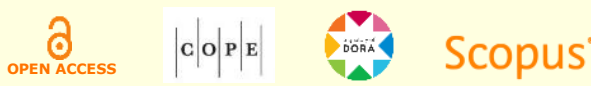


Wright, J. T., Silva, A. T. B., \& Spers, R. G. (2010). Prospecção de cenários: Uma abordagem plural para o futuro do Brasil em 2020. Revista Ibero-Americana de Estratégia, 9(1), 56-76. https://doi.org/10.5585/riae.v9i1.1645

$\mathrm{Xu}, \mathrm{M} .$, \& Kaye, R. (2009). The nature of strategic intelligence, current practice and solutions. Selected readings on strategic information systems. Hershey, PA: Information Science Reference.

\section{Author contributions}

$1^{\text {st }}$ author: conceptualization (equal), formal analysis (lead), methodology (equal), writing-original draft (lead), writingreview and editing (lead).

$2^{\text {nd }}$ author: conceptualization (equal), formal analysis (supporting), methodology (equal), supervision (lead), writingoriginal draft (supporting), writing-review and editing (supporting).

\section{Authors}

\section{Amanda Cainelli}

Universidade Federal do Rio Grande do Sul, Escola de Administração

Rua Washington Luiz, 855, Centro Histórico, 90010-460, Porto Alegre, RS, Brazil

amanda.cainelli@ufrgs.br

(iD) https://orcid.org/0000-0002-1415-5770

\section{Raquel Janissek-Muniz}

Universidade Federal do Rio Grande do Sul, Escola de Administração

Rua Washington Luiz, 855, Centro Histórico, 90010-460, Porto Alegre, RS, Brazil

rjmuniz@ufrgs.br

(iD) https://orcid.org/0000-0002-0657-6559 


\section{Appendix}

\section{Delphi questionnaire}

\section{CONDITIONS RELATED TO THE PRE-ADOPTION STAGE OF A STRUCTURED INTELLIGENCE PROCESS}

Identification: What is your relationship with the topic of Intelligence?

( ) Director / Manager / Coordinator of an Intelligence area

( ) Analyst / Intelligence Specialist

( ) Independent Intelligence Professional (consultant)

( ) Student of Intelligence

( ) I'm a consumer of Intelligence products in my company

( ) Other. Specify:

In which industry do you act?

Enter your email to receive the results of this round.

There will be 28 statements so that you objectively judge how much you agree with them being (1) totally disagree and (5) totally agree. To judge each statement, you must think about which elements are important to evaluate before the Intelligence process is implemented in order to compose a diagnostic script.

You will also be asked, if possible, to justify your response based on experiences and report any practical situations you may have experienced in accordance with the focus of each statement.

\begin{tabular}{|c|c|c|c|c|c|c|c|c|}
\hline & & & 1 & 2 & 3 & 4 & 5 & Justify \\
\hline 1 & ORG1 & $\begin{array}{l}\text { Before adopting a structured Intelligence process, the organization must } \\
\text { consider it as an important part of its strategic planning. }\end{array}$ & & & & & & \\
\hline 2 & ORG2 & $\begin{array}{l}\text { Before adopting a structured Intelligence process, the organization must } \\
\text { have an information-driven organizational culture. }\end{array}$ & & & & & & \\
\hline 3 & ORG3 & $\begin{array}{l}\text { The adoption of the structured Intelligence process requires a prior } \\
\text { definition of objectives. }\end{array}$ & & & & & & \\
\hline 4 & ORG4 & $\begin{array}{l}\text { The adoption of the structured Intelligence process requires a prior } \\
\text { definition of the organizational structure that will be involved in it. }\end{array}$ & & & & & & \\
\hline 5 & ORG5 & $\begin{array}{l}\text { The adoption of the structured Intelligence process requires a prior } \\
\text { definition of the financial resources that will be spent in its execution. }\end{array}$ & & & & & & \\
\hline 6 & ORG6 & $\begin{array}{l}\text { Before adopting a structured Intelligence process, the organization must } \\
\text { establish a committee, team or working group of people in charge, aligned } \\
\text { and motivated to carry out the process in the organization. }\end{array}$ & & & & & & \\
\hline 7 & ORG7 & $\begin{array}{l}\text { Prior top management support is decisive for the adoption of a structured } \\
\text { Intelligence process. }\end{array}$ & & & & & & \\
\hline 8 & ORG8 & $\begin{array}{l}\text { The structured Intelligence process must define, in advance, leaders } \\
\text { designated and legitimized by the organization. }\end{array}$ & & & & & & \\
\hline 9 & IND1 & $\begin{array}{l}\text { The sharing of knowledge is an essential personal skill of the Intelligence } \\
\text { professional. }\end{array}$ & & & & & & \\
\hline 10 & IND2 & $\begin{array}{l}\text { Owning and using informal or individual channels is an essential personal } \\
\text { skill of the Intelligence professional. }\end{array}$ & & & & & & \\
\hline 11 & IND3 & $\begin{array}{l}\text { Motivation to learn about relevant business Environments is an essential } \\
\text { personal skill of the Intelligence professional. }\end{array}$ & & & & & & \\
\hline 12 & IND4 & $\begin{array}{l}\text { Specialized technical education is an essential prerequisite for hiring } \\
\text { Intelligence professionals. }\end{array}$ & & & & & & \\
\hline 13 & IND5 & $\begin{array}{l}\text { Employees must be previously aware that the organization will adopt a } \\
\text { structured Intelligence process. }\end{array}$ & & & & & & \\
\hline
\end{tabular}




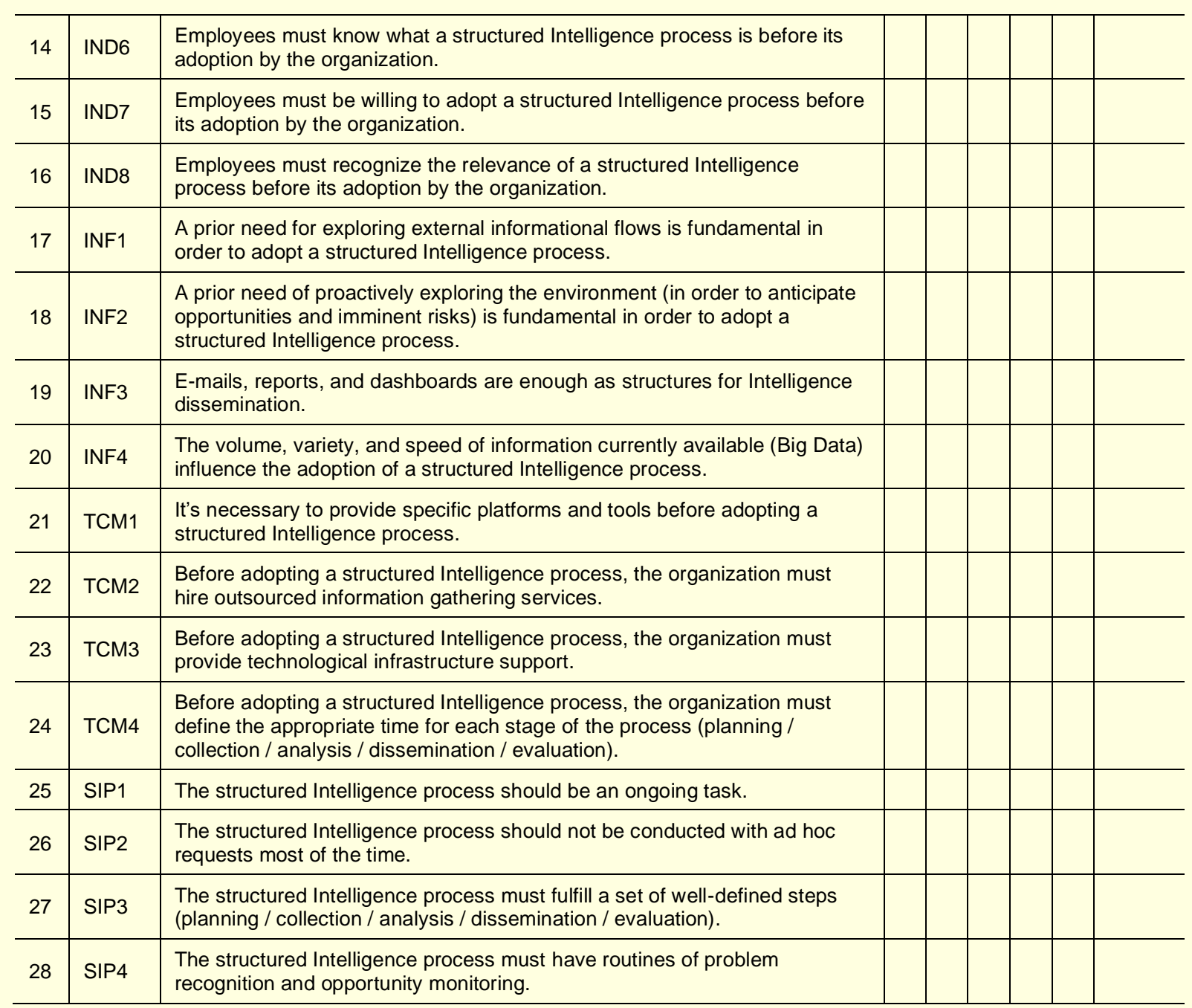

